\title{
Pathologic Stage IIIB Gastric Cancer AJCC v8
}

National Cancer Institute

\section{Source}

National Cancer Institute. Pathologic Stage IIIB Gastric Cancer A/CC v8. NCI Thesaurus. Code C133666.

Stage IIIB includes: (T1, N3b, M0); (T2, N3b, M0); (T3, N3a, M0); (T4a, N3a, M0); (T4b, N1, M0); (T4b, N2, M0). T1: T umor invades the lamina propria, muscularis mucosae, or submucosa. T2: Tumor invades the muscularis propria. T3: T umor penetrates the subserosal connective tissue without invasion of the visceral peritoneum or adjacent structures. T4a: T umor invades the serosa (visceral peritoneum). T4b: T umor invades adjacent structures/organs. N1: Tumor with metastasis in one or two regional lymph nodes. N2: Tumor with metastasis in three to six regional lymph nodes. N3a: Tumor with metastasis in seven to fifteen regional lymph nodes. N3b: Tumor with metastasis in sixteen or more regional lymph nodes. M0: No distant metastasis. (AJCC 8th ed.) 